\title{
Incentives for prosocial activities
}

\section{Economic incentives can motivate prosocial behavior, but may shift attention away from valuable altruistic activities}

Keywords: prosocial behavior, incentives, intrinsic and extrinsic motivation, over-justification effects, substitution effects, research methodology

\section{ELEVATOR PITCH}

Early studies often found that offering economic incentives for undertaking prosocial and intrinsically motivated activities can crowd out motivation to perform these activities. More recent work highlights nuanced and important features related to whether crowding out (or substitution) is likely to occur. In many cases, incentives succeed in encouraging more prosocial behavior and are also cost-effective. However, although the substitution of external incentives for intrinsic motivation may not be a concern in many contexts, the substitution of one prosocial activity for another or shifts in activities over time or location may warrant further attention.

\section{KEY FINDINGS}

\section{Pros}

๑ Economic incentives provide additional motivation to perform prosocial and intrinsically motivated activities in many different contexts.

๑ Non-profit organizations can apply standard economic principles to motivate their contributors.

- Incentives can be managed to positively direct the supply of prosocial activities to periods, places, or activities with larger imbalances between demand and supply.

(4) Most of the incentives that have been found to be effective are also relatively inexpensive.

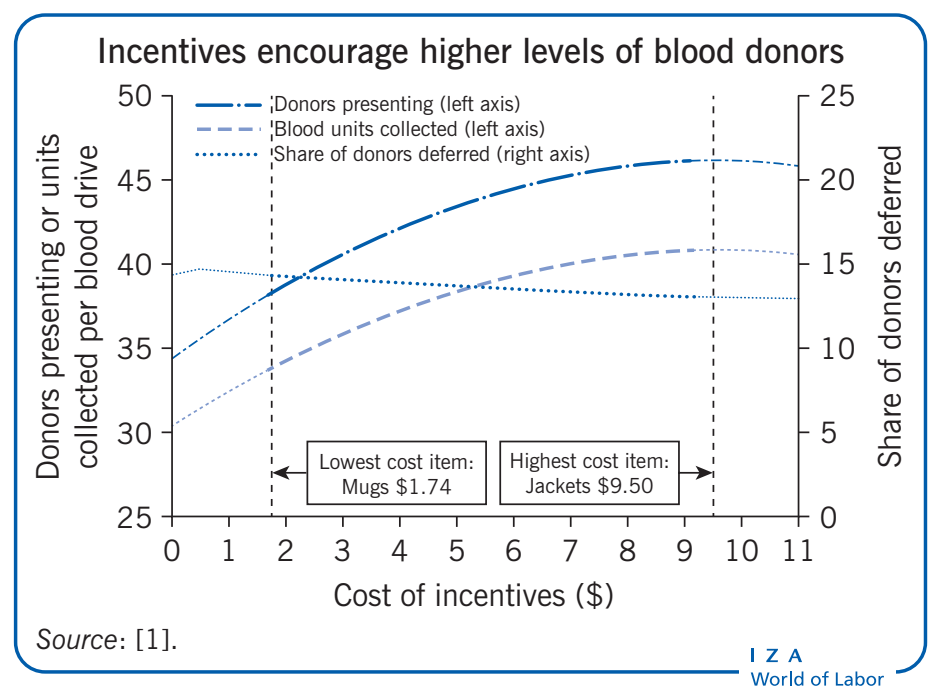

\section{Cons}

- If incentives lead to substitution effects over time or space or in the type of activity performed, their impact can be diminished.

- Ethical and cultural values might limit the adoption of incentives in certain places or lead to different responses to the same incentive.

- Institutional details, which are important in determining the success of incentive programs, can be costly to address.

- When incentives are viewed as payments for services rather than as signs of gratitude, they may reduce prosocial behavior.

\section{AUTHOR'S MAIN MESSAGE}

Because the supply of prosocial and intrinsically motivated activities often falls short of demand, organizations and policymakers sometimes use economic incentives to encourage additional supply. Properly designed incentives can increase prosocial activities without undue "crowding out" effects. However, the success of reward programs depends on how incentives are designed and framed, how rewards are characterized, and whether potential donors are familiar with the use of incentives. Potential substitution effects within a given activity or between activities also play a critical role. 


\section{MOTIVATION}

Many social and public goods are provided through the performance of volunteer activities; for example, donating blood, cleaning beaches, assisting the elderly, and working in soup kitchens. Such actions are known as "prosocial behavior." This behavior is not limited to individual initiatives or to non-profit organizations; it also occurs within profit-seeking companies, to the point of being part of the culture and mission of many corporations. As such, these activities represent an important aspect of how a society operates.

In many countries and for many activities, even though a large share of the population engages in giving and volunteering time and money, the supply of such activities still frequently falls short of demand. The availability of blood for transfusions, for example, is often below the minimum required inventory in many countries, especially at certain times of the year. Calls to engage people in volunteering and donating blood or money are common everywhere.

A simple economic explanation for this demand-supply imbalance is that the provision of these services entails costs that outweigh the individual benefits in many cases. This opens up the possibility of using additional incentives, including economic rewards, to encourage greater supply. However, using incentives for prosocial activities has been a topic of debate and controversy. Testing the effectiveness of incentives, moreover, presents several challenges; for example, in addition to the "direct" impact of incentives, it is important to consider the potential substitution effects of incentivesin time, location, and type of activities performed.

\section{Substitution effects of incentives}

Substitution effects (also referred to as "displacement" or "crowding-out" effects) occur when incentives for a certain activity lead individuals to shift their attention away from other valuable activities and towards the incentivized activity.

\section{DISCUSSION OF PROS AND CONS}

Although this paper considers several activities conducted in multiple settings, it relies heavily on studies that use the case of blood donation to illustrate the main tradeoffs involved in providing incentives for prosocial activities. Donating blood is a socially relevant activity and, in fact, the debate about the effectiveness of offering incentives for prosocial behavior (and more generally, intrinsically motivated activities) originated in early research on how to motivate blood donations.

\section{Evidence of the negative impacts of material rewards}

In 1970, publication of the book The Gift Relationship by the social scientist Richard Titmuss shook traditional economic thinking on the role of offering incentives for certain activities [2]. With particular reference to the procurement of blood for 
transfusions, Titmuss claimed that a system based on payments, like the one in the US at the time, had two major drawbacks compared with a system of uncompensated donations, as seen in the UK. First, if incentives were provided, people with less desirable characteristics would choose to supply blood-in particular poorer individuals in greater need of those rewards, but who, in turn, would be more likely to carry transmissible diseases such as hepatitis. This "adverse selection" effect would likely reduce the amount of blood actually available for transfusion and the overall quality of the blood supplied. Second, offering material rewards would crowd out people who are motivated to donate for altruistic reasons rather than enhancing such "intrinsic" incentives (incentives based on engaging in a socially beneficial activity for its own sake rather than because of an explicit return). The final outcome, again, would be worse than in the absence of rewards. In other words, incentives for prosocial behavior may be too costly and even counterproductive.

As of early 2016, Google Scholar reports that The Gift Relationship has been cited more than 3,500 times; this is meaningful evidence of the impact of Titmuss' work. Further, its influence is not limited to academic circles but also extends to policymaking. Several studies on blood donations provide evidence that appears to support Titmuss' claims. Surveys and laboratory experiments document a negative impact of compensation on the willingness of individuals to donate. Studies also find that people who are more responsive to economic incentives are more likely than others to report behaviors or disease histories that would make them ineligible to be donors [3].

Titmuss' views on the negative effects of material rewards for prosocial activitiestogether with similar claims in the psychology literature arguing that external incentives may decrease a person's intrinsic motivation to perform an activity (the "over-justification effect")-became the conceptual basis for several analyses of prosocial and, more generally, intrinsically motivated activities that find that economic incentives can backfire. An interesting example concerns the negative effect on the willingness to have a nuclear waste site in one's neighborhood generated by an offer of compensation to accept the site [4]. Other studies have documented a negative effect of incentives for prosocial behavior in the case of small rewards but not for higher payments [5].

Recent theoretical models account for the possibility that, on the one hand, incentives for prosocial behavior can have positive effects, but also that, on the other hand, they can lead to lower provision if individuals are afraid of a loss of social or self-image. Some people might view the acceptance of a reward as a signal to others (as well as to themselves) that their intrinsic motives are not strong enough to perform a prosocial activity (or are not the real motives), and thus they may prefer not to perform the activity at all rather than have their motives questioned [6].

\section{Evidence of a positive impact of material incentives}

In contrast to the claims and evidence discussed above, the basic economic argument in favor of the use of incentives is that in cases where intrinsic motivations are not strong enough relative to the costs of a certain activity (such as giving blood), and 
where the supply of the activity is below societal needs, explicit rewards may provide the additional motivation needed to overcome the costs for at least some people. More recent research, much of it based on analyses of observational data from large representative samples or on randomized field experiments, has consistently presented evidence that supports this economic argument. These studies find that providing material incentives does not necessarily crowd out prosocial and intrinsically motivated effort and, in many cases, enhances generosity by adding additional motivations to the intrinsic ones.

Looking again at blood donations as a typical example, recent studies conducted in several countries found that various incentive items, from T-shirts to gift cards to time off from work, lead to an increase in the supply of blood. Importantly, these incentives have worked to increase blood donations without attracting a larger share of donors whose characteristics make them undesirable or even ineligible to donate. Additional analyses also find evidence of a "social spillover" effect of incentives, whereby individuals who have information about the rewards offered at a blood drive plausibly spread the word to other potential donors who are unaware of the rewards, encouraging them to donate blood as well [3].

A positive effect of material incentives was recently documented for a number of other activities that, because they are likely also driven by intrinsic motivation, have been considered unresponsive to higher compensation or, more generally, to material rewards and monitoring. As in the case of donating blood, the negative effect was thought to operate both through the attraction of people with inferior abilities and undesirable attitudes toward these activities and through motivational substitution or crowding out. For example, activities such as pro-environmental behavior, healthrelated work, the willingness to become a public servant, as well as teaching in schools were considered hard to motivate other than through the intrinsic predisposition of individuals. The evidence, however, is proving that these concerns are unfounded [7], [8], [9], [10].

In some cases, researchers have also been able to observe behavior in the long term, after the intervention has ended. One concern is that motivational crowding out might not show up as long as the incentives are present but will emerge after incentives are removed because people have grown to expect to be rewarded for performing a given activity. When such long-term evidence was available, studies did not find that the provision of the prosocial or intrinsically motivated activity decreased. For example, blood donors did not donate less after an incentive was removed than they did before the incentive was introduced [3]. Also, in a field experiment of the effects of monitoring plus incentives for attendance in informal education centers in rural India, teacher absenteeism declined significantly in the schools offering the incentive ("treatment") both during and after the treatment period (Figure 1) [10].

Even if incentives are able to increase the supply of prosocial activities, there may be concerns about their cost-effectiveness. In particular, the value of the additional provision of a given activity motivated by the incentive may not compensate for the additional costs of providing rewards to all those performing the activity (or the cost of reaching a desired level for an activity), including those who would have supplied the activity even without the external incentive. The balance of the evidence in the long-term studies shows, however, that the incentives were cost-effective [3], [10]. 
Figure 1. Teacher attendance rates are higher in Indian nonformal education centers that Creceive monitoring and extra incentives

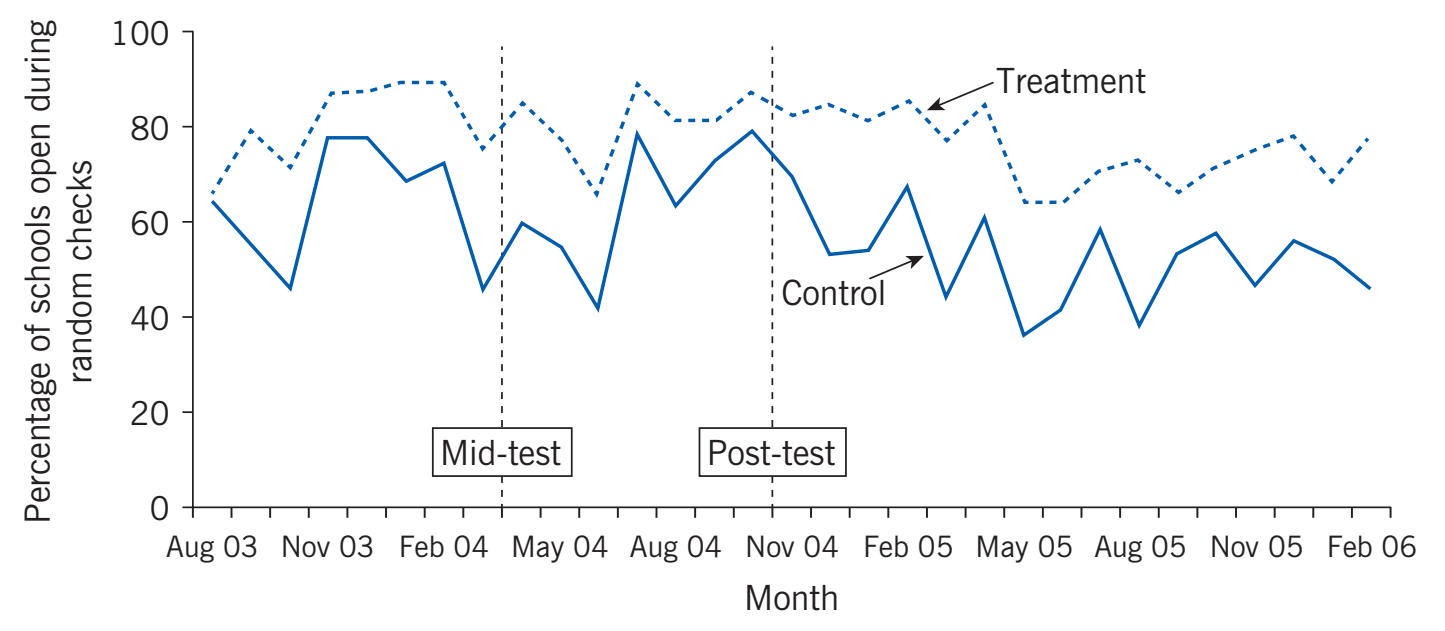

Source: Based on Duflo, E., R. Hanna, and S. P. Ryan. "Incentives work: Getting teachers to come to school." American Economic Review 102:4 (2012): 1241-1278 [10].

Nevertheless, this may not always be the case. For example, in one incentive program in Italy, intended to increase blood donations, donors received a full paid day off from work, with the cost covered by the central government. That was a very costly reward, and the extra blood collected as a result might not have been enough to compensate for the cost of rewarding everyone who donated, including those who would have donated without the incentive [3]. But, again, the high cost of this incentive program is an exception, according to the current evidence, rather than the rule.

\section{What accounts for the differences in findings?}

Differences in methodology and in attention to institutional details are the most likely explanations for the contrary findings of the two sets of studies described above. A common feature of the research that finds negative effects of incentives is that the studies are based on respondents' stated preferences. By contrast, the work that finds evidence of positive effects is based on actual observed behavior. Another difference is that participants in the studies that find negative effects of explicit rewards were in most cases aware of being observed. For example, subjects in laboratory experiments were told that they were part of a study and what the objective of the study was, or participants reported their preferences through face-to-face interviews [4]. In contrast, individuals who were the subjects of the studies that find positive effects were not aware of being observed.

Several studies have analyzed the discrepancies between what people say and what they do when exposed to incentives, especially in the case of socially or ethically charged activities [11]. When asked in surveys or in interviews how they would behave in certain hypothetical situations, individuals may respond with what they believe the researchers or society considers to be the socially acceptable answer rather than with 
what they actually intend to do. For example, if there is a stigma attached to being rewarded for actions that are viewed as driven exclusively by altruism and in which self-interest should play no part, subjects may choose to conform to the prevailing social norm in their answers. People might also want to see themselves in a positive light, as someone who contributes to the public good only out of a desire to help others rather than for a reward. In both cases, individuals may report that economic incentives would not increase their participation in a socially desirable activity and that it might even reduce it [11]. Evidence from field trials and natural settings, in contrast, is based on observations of the actual behavior of individuals who are not aware that they are part of a study. Thus, they are less likely to repress incentive-based motives.

Attention to institutional details is also important. The studies on blood donations described above show that the way in which rewards are presented may influence whether they successfully motivate more donations from desirable donors. For example, most of the incentives offered in the field studies were in the form of noncash rewards [3]. People may view these rewards less as a form of direct payment than as a demonstration of "gratitude" and therefore may interpret the rewards more positively. Another relevant institutional feature in most of the studies reporting positive effects of incentives is that potential donors were likely already familiar with the use of such rewards [3]. In contrast, several hypothetical studies that find negative effects of incentives confront subjects with scenarios with which they are less familiar, thus raising additional questions about respondents' stated negative attitude toward incentives [3]. In addition, most naturally occurring incentive programs, such as distributing small reward items in certain blood drives organized by the American Red Cross, are unconditional: rewards are distributed to anyone who shows up at the blood drive, regardless of whether they donate blood or whether their blood donation is discarded after the blood is tested for diseases. Because of this feature, people have no obvious reason to provide false information about their health or past risky behavior in order to receive a reward.

In summary, the methodological approaches employed in the more recent studies that find positive effects for incentives convey greater credibility to their findings than do those of studies that report negative effects. The current balance of the evidence favors the claim that incentives do motivate people to provide public goods and engage in prosocial activities. As such, economic incentives are a useful and relatively simple means to reduce the gap commonly found between the demand for and supply of these activities. However, the apparent importance of institutional details in determining the success of extrinsic rewards means that easy generalizations cannot be drawn beyond the contexts that have been analyzed so far.

\section{A "general equilibrium" view of the effect of incentives: Substitution effects}

In the summer of 2014, charitable giving became a news sensation thanks to the "Ice Bucket Challenge." The origins of the challenge are still unclear, but it consisted of individuals posting videos on social media of themselves having ice water poured over their heads and inviting their friends to do the same or to donate $\$ 100$ to the 
ALS Association, a non-profit organization that promotes research and awareness about amyotrophic lateral sclerosis (or Lou Gehrig disease). The challenge went viral, thanks in part to the participation of numerous celebrities. Over July-August 2014, donations to the ALS Association reached $\$ 100,000,000$ in the US alone, an increase of about $3,500 \%$ over the amount collected in the same period of the previous year. A number of reasons were proposed to explain the success of the initiative, including the demonstration effects of participation by celebrities, the "network effects" generated by social media, the low barriers to entry, and a mix of incentives such as social recognition and narcissism.

However, criticisms of the campaign soon emerged. Some questioned whether the results of the initiative were really as positive as they appeared and asked whether there were also some implied hidden costs that were being overlooked. Arguments for such hidden costs drew on the substitution effect from the standard theory of incentives: when the incentives for a given activity increase, individuals might shift their attention, effort, and additional resources away from other activities and toward the activity offering the additional incentive [12]. The net or general effect of additional motivations to perform one activity may therefore be smaller than a simple consideration of the direct impact would imply. If the extra or "marginal" effort (or money) devoted to an incentivized activity is less effective in that activity than it would be if employed in another activity, there could even be a net social loss.

Evidence from specific cases regarding the performance of prosocial activities suggests that this substitution effect is likely to occur. A survey by the non-profit organization Giving What We Can, for example, finds that contributors reported that they would have made donations to other causes valued at about half of their donations to a given cause (reported in [12]).

If society cares about the overall contribution to prosocial activities and about the optimal allocation of effort, time, and money across these activities, then systematic analyses are needed to investigate substitution patterns across activities and how incentives for just some activities may affect overall outcomes. Two studies of the effect of incentives for blood donations looked at what happened at numerous American Red Cross blood drives in northern Ohio in the US when only a subset of the drives were offering rewards at a given time [1], [3]. These differences across drives and time periods allowed researchers to assess both geographic and temporal displacement effects of the incentives. The studies found that part of the increase in donations at blood drives offering rewards came from a reduction in turnout at neighboring blood drives that were not offering any extra incentive to donate. The evidence also indicated that people were modifying the timing of their donations, switching them to coincide with periods when incentives were provided.

Substitution effects may also arise in more subtle ways, akin to "moral self-licensing" [13]. For example, some people, after performing one or more prosocial acts, might then feel entitled to be less prosocial in the future. To the extent that economic incentives motivate the performance of altruistic activities, they may also exacerbate moral self-licensing effects. 


\section{LIMITATIONS AND GAPS}

The response to incentives is likely to depend on the specific institutional arrangements as well as on prevailing social norms and values in a given community, including the moral beliefs about receiving compensation for engaging in prosocial activities. The importance of institutional arrangements and norms means that generalizations cannot be drawn beyond the contexts that researchers have analyzed so far. Although studies have already investigated multiple contexts, activities, and rewards, additional evidence is needed from yet other settings in order to provide a more complete view of the impact of incentives on prosocial behavior. This broader context is particularly important for studies of substitution patterns, about which not enough is known.

We need more systematic analyses of substitution patterns across the range of prosocial activities and of how incentives for some activities affect cumulative outcomes. This gap in the investigation is due in part to the demanding data requirements for a study of substitution effects. For example, data would be required on multiple activities, with only some of them being incentivized, or on a given activity that is performed in different locations or over different time periods. This information is obviously more difficult to obtain than data on a single activity, location, or time period.

Moreover, because the gap between the demand for and supply of public goods is typically greater in developing countries, more evidence needs to be collected especially for developing countries. Investigating the impact of incentives in different parts of the world might also provide additional sources of variation to distinguish the sources of any positive or negative effect; for example, the responses to incentives in different places may tell us whether the effects derive from general psychological mechanisms (such as over-justification) or whether they depend more on prevailing local values and beliefs.

Finally, although most studies have examined the impact of providing incentives on a one-time basis, it would be interesting to investigate the impact (and cost effectiveness) of offering rewards repeatedly.

\section{SUMMARY AND POLICY ADVICE}

Some of the earlier research on the impact of incentives on prosocial and intrinsically motivated behavior finds negative effects on willingness to donate, as well as increases in negative selection. Much of that research is based on surveys and laboratory experiments in which respondents reported on their preferences. More recent research showing positive impacts for incentives is based on actual observed behavior. Most of the current evidence shows that economic incentives, when properly designed, can enhance several types of prosocial behavior and intrinsically motivated activities. The studies showing positive impacts find little crowding out of other prosocial activities in favor of the incentivized activities and not much adverse selection, either in the short or the long term. Outcomes also appear to be influenced by differences in institutional details, such as the way rewards are presented (for example, as gratitude gifts or as a form of direct payment) and whether potential donors are already familiar with the use of incentives. 
Organizations and policymakers interested in promoting prosocial activities may benefit from using incentives as a relatively straightforward tool to engage more people in donating money and time to socially relevant causes and activities. Movements in this direction are already being observed. For example, the US Ninth Circuit Court recently ruled that compensating individuals who donate bone marrow through a particular process known as apheresis is legal, despite a federal law banning payments for human organs. In addition, privately run, for-profit plasma centers that pay individuals for their blood plasma are becoming a rapidly growing industry in the US.

When implementing incentives to encourage prosocial activities, however, organizations and policymakers ought to pay attention to potential undesirable substitution effects (over time, space, or activities) that might be exacerbated by incentives. In some cases, however, the substitution effects generated by the provision of incentives may not be negative and, indeed, may even be desirable. For example, incentives may be used to guide individuals to perform certain activities in periods or locations where their engagement will have the highest return.

A final, broad message from the evidence presented here is that in order to thoroughly understand the impact of incentives on prosocial behavior, organizations and public agencies should be open to experimenting with different solutions involving different types of incentives. Evidence-based policies, with evidence generated using stateof-the-art research methodologies, are especially warranted when they concern the supply of socially relevant activities.

\section{Acknowledgments}

The author thanks the anonymous referees and the IZA World of Labor editors for many helpful suggestions on earlier drafts. The author is also grateful to Mario Macis for many conversations and for joint research on these topics. In fact, the author claims only partial ownership of (but full responsibility for) the considerations made above, given how large Mario's influence has been through their joint work. In addition to the work with Mario Macis, this paper has drawn on work conducted by the author in collaboration with Julio Elias, Victor lajya, Robert Slonim, and Sarah Stith.

The author dedicates this article to the memory of his dear friend and fellow doctoral student Rafel Lucea, who first inspired him to pursue research with high social impact.

\section{Competing interests}

The IZA World of Labor project is committed to the IZA Guiding Principles of Research Integrity. The author declares to have observed these principles.

(c) Nicola Lacetera 


\section{REFERENCES}

\section{Further reading}

Deci, E. L. "Effects of externally mediated rewards on intrinsic motivation." Journal of Personality and Social Psychology 18:1 (1971): 105-115.

Kamenica, E. "Behavioral economics and psychology of incentives." Annual Review of Economics 4:1 (2012): 427-452.

\section{Key references}

[1] Lacetera, N., M. Macis, and R. Slonim. "Will there be blood? Incentives and displacement effects in pro-social behavior.” American Economic Journal: Economic Policy 4:1 (2012): 186-223.

[2] Titmuss, R. M. The Gift Relationship. Crows Nest, Australia: Allen and Unwin, 1970.

[3] Lacetera, N., M. Macis, and R. Slonim. "Economic rewards to motivate blood donations." Science 340:6135 (2013): 927-928.

[4] Frey, B. S., F. Oberholzer-Gee, and R. Eichenberger. "The old lady visits your backyard: A tale of morals and markets." Journal of Political Economy 104:6 (1996): 1297-1313.

[5] Gneezy, U., and A. Rustichini. "Pay enough or don't pay at all." The Quarterly Journal of Economics 115:3 (2000): 791-810.

[6] Bénabou, R., and J. Tirole. "Intrinsic and extrinsic motivation." The Review of Economic Studies 70:3 (2003): 489-520.

[7] Rommel, J., V. Buttmann, G. Liebig, S. Schönwetter, and V. Svart-Gröger. "Motivation crowding theory and pro-environmental behavior: Experimental evidence." Economics Letters 129:1 (2015): 42-44.

[8] Ashraf, N., O. Bandiera, and S. S. Lee. Do-gooders and Go-getters: Career Incentives, Selection, and Performance in Public Service Delivery. Harvard Business School Working Paper, 2015.

[9] Dal Bo, E., F. Finan, and M. A. Rossi. "Strengthening state capabilities: The role of financial incentives in the call to public service." The Quarterly Journal of Economics 128:3 (2013): 11691218.

[10] Duflo, E., R. Hanna, and S. P. Ryan. "Incentives work: Getting teachers to come to school." American Economic Review 102:4 (2012): 1241-1278.

[11] Levitt, S. D., and J. A. List. "What do laboratory experiments measuring social preferences reveal about the real world?" Journal of Economic Perspectives 21:2 (2007): 153-174.

[12] MacAskill, W. "The cold, hard truth about the ice bucket challenge." Quartz, August 14, 2014.

[13] Merrit, A. C., D. A. Efrron, and B. Monin. "Moral self-licensing: When being good frees us to be bad." Social and Personality Psychology Compass 4:5 (2010): 344-357.

\section{Online extras}

The full reference list for this article is available from:

http://wol.iza.org/articles/incentives-for-prosocial-activities

View the evidence map for this article:

http://wol.iza.org/articles/incentives-for-prosocial-activities/map 